\title{
Comment on Xue et al.: Alendronate treatment improves bone-pedicle screw interface fixation in posterior lateral spine fusion: an experimental study in a porcine model
}

\author{
Saurabh Singh • Vikram Singh • Anil Joshi
}

Received: 6 March 2010 /Accepted: 12 April 2010/Published online: 9 May 2010

(C) Springer-Verlag 2010

We read the article entitled "Alendronate treatment improves bone-pedicle screw interface fixation in posterior lateral spine fusion: an experimental study in a porcine model" by Qingyun Xue et al. with great interest [1]. The purpose of the research was to investigate whether alendronate treatment improves bone-pedicle screw interface fixation in posterior lateral spine fusion. We would like to thank the authors for their innovative and encouraging paper, but we have some concerns about the safety profile of alendronate.

The authors advocated wider use of alendronate based on the properties of bisphosphonates for reduction of bone remodelling by inhibition of osteoclastic activity. Normal bone remodelling is linked to new bone formation by the so-called coupling phenomenon. The most effective approach to prevent implant loosening would be to have a positive balance between bone formation and resorption in the active bone-remodelling time period. Alendronate treatment could

S. Singh $(\bowtie)$

Department of Orthopaedics, Institute Of Medical Sciences,

Banaras Hindu University (IMS-BHU),

Varanasi, Uttar Pradesh, India

e-mail: drsaurabhsinh@gmail.com

V. Singh

Department of Medicine, VCSG Medical College,

Srikot, Srinagar, Pauri Garhwal, Uttaranchal, India

A. Joshi

Department of Orthopaedics, VCSG Medical College,

Srikot, Srinagar, Pauri Garhwal, Uttaranchal, India protect the bone structure from extra resorption while maintaining the bone volume around the screw surface.

In fact, prolonged suppression of bone remodelling with alendronate may be associated with a new form of insufficiency fracture of femur [2]. The fracture rate is higher in long-term use than during the first year of therapy, suggesting possible adverse effects on bone [3]. Alendronate inhibits bone resorption by suppressing activity of osteoclasts, and inducing them to undergo apoptosis. While this leads to an increase in bone mineral density (BMD) of patients with osteoporosis, treatment with alendronate has been shown to reduce bone turnover. In humans prolonged administration of bisphosphonates can lead to development of osteopetrosis or marble bone disease [4].

Keeping the above-mentioned facts in mind, authors must warn the orthopaedic community about liberal use of alendronate.

\section{References}

1. Xue Q, Li H, Zou X, Dalstra M, Lind M, Christensen FB, Bünger C (2010) Alendronate treatment improves bone-pedicle screw interface fixation in posterior lateral spine fusion: an experimental study in a porcine model. Int Orthop 34(3):447-451

2. Goh SK, Yang KY, Koh JSB, Wong MK, Chua SY, Chua DTC et al (2007) Subtrochanteric insufficiency fractures in patients on alendronate therapy: a caution. J Bone Jt Surg Br 89-B:349-353

3. Briot $\mathrm{K}$, Trémollières $\mathrm{F}$, Thomas $\mathrm{T}$, Roux $\mathrm{C}$, GRIO Scientific Committee (2007) How long should patients take medications for postmenopausal osteoporosis? Jt Bone Spine 74:24-31

4. Whyte MP, Wenkert D, Clements KL, McAlister WH, Mumm S (2003) Bisphosphonates induced osteopetrosis. N Engl J Med 349 